Western University Scholarship@Western

Geography Publications

Geography Department

4-1983

\title{
Confluence Scour in Coarse Braided Streams
}

Peter Ashmore

University of Western Ontario

Gary Parker

University of Illinois at Urbana-Champaign

Follow this and additional works at: https://ir.lib.uwo.ca/geographypub

Part of the Geography Commons

Citation of this paper:

Ashmore, Peter and Parker, Gary, "Confluence Scour in Coarse Braided Streams" (1983). Geography Publications. 295.

https://ir.lib.uwo.ca/geographypub/295 


\title{
Confluence Scour in Coarse Braided Streams
}

\author{
Peter Ashmore \\ Department of Geography, University of Alberta, Edmonton, Alberta, T6G $2 \mathrm{H} 4$ Canada
}

Gary Parker

St. Anthony Falls Hydraulic Laboratory, Department of Civil and Mineral Engineering, University of Minnesota

Minneapolis, Minnesota 55414

\begin{abstract}
Laboratory models of a braided valley flat in coarse material were used in conjunction with field data to study confluence scour at braid anabranches. Correct prediction of the depth of scour is required for the design of buried pipeline crossings. Braid pattern and anabranches constantly shift and avulse so that scour holes have definable lifetimes. Although the scatter is large, the depth of water in the scour hole depends on confluence and relative anabranch discharge; this depth can be as high as six times the ambient depths in the anabranches.
\end{abstract}

\section{INTRODUCTION}

Confluence scour in braided streams, a key factor in the design of buried pipeline crossings, has received relatively little attention. The designers of the Alaskan pipeline, for example, were faced with designing crossings with no data on which to base scour predictions [Doyle and Childers, 1975]. Future oil and gas development in the Arctic will undoubtedly necessitate the construction of more pipelines across the mountainous terrain of Alaska, the Yukon, the Northwest Territories, and Southwestern Canada and will involve crossing many gravel braided streams. Confluence scours are also geomorphologically important as nodes in the channel network, which control the distribution of sediment downstream and hence the pattern of bar construction and channel migration [Ashmore, 1982]. At present it can be said that no comprehensive field measurements are available with which to determine the main controls on scour depth and form and on which design relations could be based.

Obtaining scour measurements from these steep, swift streams at high flow can be extremely hazardous. Often it is impossible to gain access to suitable confluences, and the turbid water during high stages makes it impossible to see the form of the channels and scour holes. If a model of a braided stream can be produced in the laboratory, confluence scour can be studied under more manageable conditions. Such a model allows an understanding of the relation of confluence scour to anabranch migration, amalgamation, and bifurcation to be obtained. If a scour relation can be developed from the laboratory model and a law allowing the scaling up of the scour relation to predict the field case can be obtained, then the laboratory data are of quantitative value in the prediction of scour in the field.

This paper presents the results of laboratory modeling of confluence scour in coarse braided streams and compares laboratory data with field data using an appropriate scaling law. The major controls of scour depth are isolated and may be used for design predictions.

Copyright 1983 by the American Geophysical Union.

Paper number $2 W 1752$.

0043-1397/83/002W-1752\$05.00

\section{PreVious Research}

Neither confluence scour nor the broader problem of the mechanics of braided streams have been studied intensively by engineers. Much of the engineering literature has concentrated on the conditions for the occurrence of braiding [Lane, 1957; Henderson, 1966; Callander, 1969; Engelund and Skovgaard, 1973; Parker, 1976] from either an empirical or theoretical point of view. Some studies of the mechanics of gravel braided streams exist [e.g., Galay, 1971; Griffiths, 1979], but surprisingly little reference is made to local scour. Recent work by Mosley [1981] on the Ohau River, New Zealand, is probably the first attempt to arrive at some design criteria for confluence scour using field data. Based on measurement of nine scour holes, Mosley tentatively proposed a design curve based on the relationship between scour depth and the total discharge through the scour hole. The geomorphologic and sedimentologic literature contains several studies of aspects of the mechanics of braided streams, and a number of these mention the presence of deep scour holes [Fahnestock and Bradley, 1973; Smith, 1973; Smith, 1974; Hein and Walker, 1977], but most make only passing reference to them. Fahnestock and Bradley [1973] reported a confluence scour on the Knik River, Alaska, 15 feet $(4.575 \mathrm{~m}$ ) deep ( 3 or 4 times the depth of the incoming channels). D. Smith, in reporting depths of 4-10 feet (1.22-3.05 $\mathrm{m}$ ) in scour pools on the North Saskatchewan River, Alberta, Canada, remarked, 'Depths of these pools are deceiving and dangerous to the neophyte doing field work,' [Smith, 1973]. However, as in the engineering literature, little field data have yet been collected to analyze the factors controlling the depth of scour.

Friedkin [1945] was one of the first to report observations of braiding from a laboratory model, and since then a number of such studies have been attempted [Leopold and Wolman, 1957; Schumm and Khan, 1972; Kinoshita, 1979; Hong and Davis, 1979; Anderson et al., 1975; Southard et al., 1981; Ashmore, 1982]. Most of these models exhibited a low degree of braiding (except in the case of Hong and Davies, whose model was at a much smaller scale than the others and was intended to model the channel network characteristics rather than the details of the channel form). Of these studies, only Ashmore's makes anything more than a passing reference to the presence of local scour in braided streams.

The most detailed laboratory study of confluence scour is 


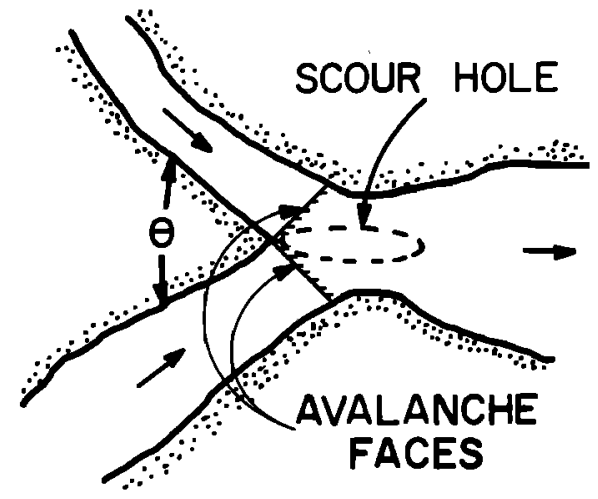

Fig. 1a. Definition diagram showing lens-shaped scour hole. The two upstream channels are of equal strength.

that of Mosley [1976]. Rather than model an entire valley flat, he studied a simple fixed Y-shaped confluence under controlled conditions in a small flume containing cohesive sediment with a median diameter of $0.34 \mathrm{~mm}$ and a silt/clay content of $19 \%$. This approach, nevertheless, served to illustrate most of the qualitative aspects of confluence scour under conditions of active bedload transport. Mosley found that the scour holes were typically lens-shaped in plan, as shown in Figure $1 a$. The water surface above the scour hole is superelevated, and flow through the hole displays a pair of back-to-back helicoidal vortices that are responsible in part for its excavation. This structure suggests some relationship between confluence scour and scour at the outside of bends. In passing through the Y-shaped confluence, fluid streamlines must curve as if they were going around a bend. The resulting centrifugal acceleration sets the stage for both the superelevation and scouring helicoidal flow. The scour hole bears some resemblance to one that would be produced by two bends placed back-to-back (Figure $1 b$ ).

Mosley's study indicates that scour depth increases with the angle of incidence $\theta$ at which the upstream anabranches meet. An increase of $\theta$ implies a decreased radius of curvature of the streamlines of the primary flow as they pass through the confluence, which agrees with the observation from bend scour experiments that scour depth is inversely related to the radius of curvature of the bend. Mosley also found that for a given total discharge in the two channels, the depth of scour decreases as the discharge becomes concentrated in one of the anabranches at the expense of the other. While these two factors (angle of incidence and relative discharge of the two channels) were dominant, Mosley also demonstrated that an increase in the total sediment load could produce a reduction of scour depth of up to $25 \%$ over a four-fold increase in sediment load when all other factors remained unaltered. Ashmore [1982] confirmed the presence of the secondary flow cells described by Mosley but reported only weak relationships between scour depth and angle of incidence $\theta$ for scours with varying total discharge.

Confluence scour, in addition to resembling back-to-back bend scour, can also be seen to be analogous to scour in a lateral constriction. Indeed such scour is common in braided streams also [Smith, 1973; Hein and Walker, 1977]. The rapid flow at the constriction can be described as a wall jet flowing tangentially to an erodible bed. Scour holes produced by wall jets of simplified geometry have been studied by a number of researchers, for example; Rajaratnam and Berry [1977]. The shape of these scour holes closely resembles that of braid con- fluence scour. Under certain tailwater conditions, slip faces resembling those seen downstream of confluence scours form downstream of these jet scours [Rajaratnam et al., 1981]. The major difference between the two is that most studies of jet scour have utilized clear water in the jet; the scour hole tends towards a static state. The 'jet' of confluence scour is usually laden with sediment, and any equilibrium geometry is dynamic in nature.

\section{Modeling of Gravel Braided Streams}

Parker and Anderson [1975] raised the possibility of fairly detailed modeling of gravel bed streams by using sand in laboratory river trays and Froude similarity principles. This possibility was realized in Ashmore's $[1979,1982]$ model of an entire valley flat and also recently by Southard et al. [1981]. Ashmore's model was used to describe processes of bar formation, channel shifting, and local sediment size sorting. The presence of confluence scour was noted and a description of its characteristics given together with measurements of the hydraulic geometry of model anabranches.

The accuracy of the model was checked by the measurement of the parameters of hydraulic geometry: cross-sectionally averaged depth $H$, water surface width $B$, and discharge $Q$ at bankfull or formative stage. Since active channels were always undergoing changes in cross section form, the measured discharge of an active, well-developed anabranch at a given time was taken to be its formative discharge at that time.

Parker [1979] introduced the concept of dimensionless hydraulic relations for gravel streams;

$$
\begin{aligned}
H^{*} & =f_{1}(\tilde{Q}) \\
B^{*} & =f_{2}(\tilde{Q})
\end{aligned}
$$

where

$$
H^{*}=\frac{H}{D_{50}} \quad B^{*}=\frac{B}{D_{50}} \quad \tilde{Q}=\frac{Q}{\left(R g D_{50}\right)^{1 / 2} D_{50}{ }^{2}}
$$

where $D_{50}$ is the median bed surface grain size, $g$ the acceleration due to gravity, and $R$ the submerged specific gravity of the sediment (near 1.65 in most cases). It is shown by Parker that two gravel streams (and by extension, two anabranches), with different values of $D_{50}$ but with the same slope $S$ and dimensionless discharge $\tilde{Q}$, exhibit Froude similarity so that $f_{1}$ and $f_{2}$ of $(1 a)$ and $(1 b)$ are the same for the two cases and $H^{*}$ and $B^{*}$ are approximately identical.

By extension, as long as Reynolds effects are not large, a sand bed laboratory stream can be used to model a field gravel braided stream. Similarly, as long as laboratory tray slope and field valley slope coincide and both are wide enough to allow for several self-formed anabranches, one set of anabranches

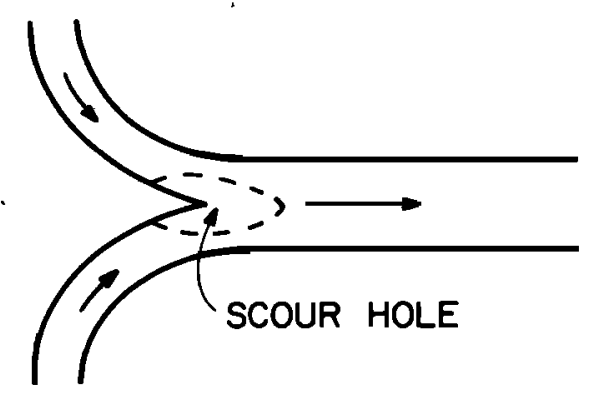

Fig. 1b. Scour produced by back-to-back bends. 
should model the other in the sense that both data sets obey the same dimensionless hydraulic relations ( $(1 a)$ and $(1 b))$.

In Figure 2, data for $B^{*}, H^{*}$, and $\tilde{Q}$ are plotted for Ashmore's [1979] experimental anabranches and field anabranches from the Sunwapta River, Alberta, Canada [Rice, 1979]. The portion of the Sunwapta River from which the data were collected is a steep and braided reach about $10 \mathrm{~km}$ downstream from the glacial source of the river. The bed material is coarse, mainly gravel. The valley flat slope ranges from 0.013 in the upstream part of the reach, declining to 0.005 at the downstream end. This decline in slope is accompanied by a reduction in the $D_{50}$ of bed material samples from about $70 \mathrm{~mm}$ to about $8 \mathrm{~mm}$. The river tray slope was 0.013 , and $D_{50}$ in the anabranches was between 1.2 and $1.8 \mathrm{~mm}$. The two data sets coincide fairly well despite differences in channel slopes, as could have been predicted from Parker's [1979] results for single channels. The dimensionless depths for the laboratory anabranches plot somewhat low; this is likely due to a weak Reynolds effect [Parker et al., 1982]. The comparatively small range of values of $\tilde{Q}$ in the laboratory compared with the field may also contribute to differences between the two sets shown in Figure 3. However, it is clear that a dimensionless relation determined solely from laboratory data would give reasonably accurate results when applied to the Sunwapta River within the same range of $\tilde{Q}$. In this sense, one models the other.

The above result suggests that an appropriate dimensionless relation for confluence scour depth determined in the laboratory model would also apply to field streams similar to the Sunwapta River. This paper examines that likelihood.

\section{Data Collection}

Data on confluence scour were collected from laboratory models in two different sands and from the field. The intention was to extend Mosley's [1976] analysis to self-formed confluences with a simple geometry similar to Mosley's Y-shaped form.

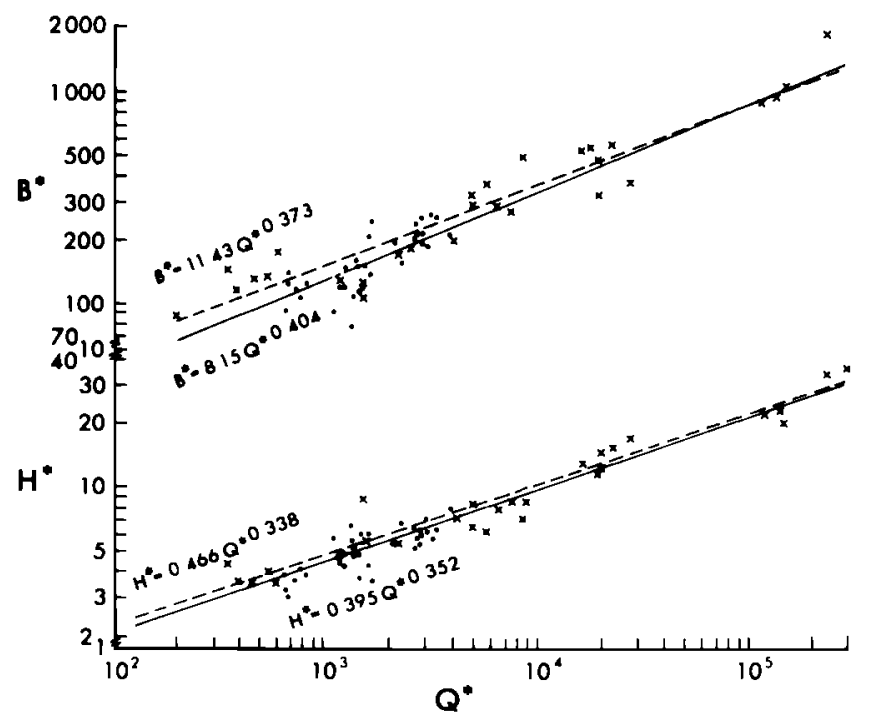

- Model channels

* Sunwapta channels

Sunwapta channels All data

Fig. 2. The $B^{*}-\tilde{Q}$ and $H^{*}-\tilde{Q}$ relations for anabranches for Sunwapta River, Alberta, Canada, and laboratory anabranches. From Ashmore [1982].

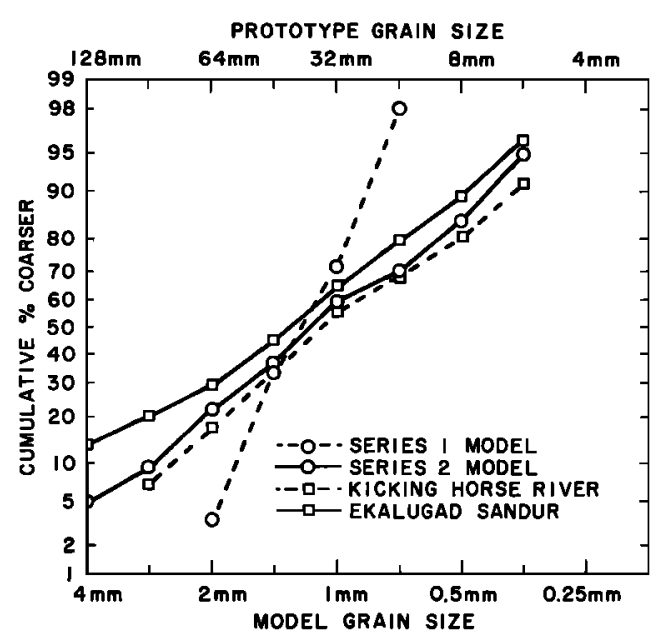

Fig. 3. Comparison of sediment size distribution of the two laboratory sands and prototype gravel braided streams.

\section{EXPERIMENTAL APPARATUS}

Two river trays were used in the laboratory experiments. The first, containing well sorted sand, was $10 \mathrm{~m}$ long and $1.3 \mathrm{~m}$ wide. The sediment used (Figure 3) had $D_{50}$ of $1.1 \mathrm{~mm}$ and geometric standard deviation $\sigma_{g}$ of 1.3 , determined from dry sieving. Submerged specific gravity $R$ was 1.63 . Total discharge was monitored at the upstream end by means of a constant head tank. A Syntron vibration feeder was used to supply dry sediment at the upstream end. Sediment collection in the tail box was dried and returned to the feeder. The rate of sediment feed was monitored constantly.

The second river tray, which contained poorly sorted sand, was $10 \mathrm{~m}$ long and $2.3 \mathrm{~m}$ wide. The sediment used (Figure 3) was mixed so as to model typical size distributions of the gravel fraction of bed material from gravel braided streams. Two size distributions, one from Ekalugad Sandur, Baflin Island [Church, 1972] and the other from Kicking Horse River, British Columbia, Canada [Smith, 1974] are shown in Figure 3 for comparison. The $D_{50}$ of the sand was $1.11 \mathrm{~mm}$ and $\sigma_{\theta}=2.14$. The sediment and part of the water were recirculated using a portable diaphragm pump; the remainder of the discharge was pumped into the flume from the laboratory sump. Both pumps were calibrated so that the combined water discharge could be set to the desired quantity.

\section{ExPerimental Procedure}

Braided streams flowing on wide, unvegetated valley flats possess two sets of hydraulic parameters of relevance here. One set refers to the overall parameters of the valley train itself; this set includes valley train slope $S_{v}$, valley flat width $B_{v}$ across which the anabranches are free to move, total water discharge $Q_{v}$, and coarse sediment mass discharge $G_{v}$ being fed into the valley as bedload. The other set refers to the local conditions within a single anabranch: water surface slope $S_{w}$ and bed slope $S_{b}$, water surface width $B$, cross-sectionally averaged water depth $H$, discharge $Q$ and median bed surface grain size $D_{50}$.

There must be some relation between the two sets. The sum of the anabranch discharges $Q$ must equal $Q_{v}$ (assuming that groundwater flow is negligible and there is no inflow or outflow of water for the reach in question). Anabranch slope may vary but the range of variation is constrained by the overall valley slope. It was hypothesized, for the purposes of analysis, that 
TABLE 1. Parameters of Equilibrium Valley Flats

\begin{tabular}{ccccc}
\hline State & $Q_{v}, l / s$ & $G_{v}, \mathrm{~g} / \mathrm{min}$ & $S_{v}$ & $t_{E}, \mathrm{~h}$ \\
\hline$I$ & 1.00 & 60 & 0.013 & 22 \\
$A$ & 1.00 & 90 & 0.016 & 20 \\
$B$ & 1.00 & 35 & 0.010 & 30 \\
$C$ & 0.67 & 35 & 0.015 & 22 \\
\hline
\end{tabular}

confluence scour is controlled solely by local parameters, so that a scour relation need not take into account the general parameters of the valley flat. The scour observations were made under a variety of valley flat conditions in an attempt to confirm that they are not important in the scour relation.

In the well sorted sediment (referred to hereafter as Series 1), $Q_{v}$ and $G_{v}$ were chosen and fed into the flume until a state of gross equilibrium was established. This equilibrium was defined in terms of a plot of overall flume slope $S_{v}$ and sediment discharge at the downstream end of the flume. When the sediment discharge came into balance with the feed rate $G_{v}$ and $S_{v}$ was stable, it was assumed that gross equilibrium had been established. From this point on, anabranch and scour parameters were measured, holding $Q_{v}$ and $G_{v}$ constant. Four such runs with different $Q$ and $G_{v}$ were made. Table 1 lists $Q_{v}, G_{v}$, and $S_{v}$ at equilibrium and the time required to reach equilibrium. Each equilibrium state is defined by a letter $I, A, B$, or $C$; they are listed in chronological order of formation. It can be seen that for constant $Q_{v}$, equilibrium slope increases with sediment feed rate, as would be expected. In the one case where $G_{v}$ was held constant but $Q_{v}$ decreased by one third, the slope increased markedly.

In the poorly sorted sediment (referred to hereafter as Series 2), measurements were again taken at a variety of valley slopes and discharges. Equilibrium using sediment recirculation was established fairly quickly (10-15 hours). In contrast to the sediment feed system, the sediment discharge is determined by the river in response to imposed $S_{v}$ and $Q_{v}$. Between each run the sand was levelled and a straight channel with trapezoidal cross section cut down the middle of the flume. Braiding developed from this straight channel in only a few (usually $<10$ ) hours. Once the whole flume had been reworked by the braided channel or the width of the braided channel zone stopped increasing, measurement commenced. Scour measurements were taken from six runs at various combinations of slope and discharge, although over half of the data comes from one run. These runs are listed in Table 2 together with the number of scour holes measured, $Q_{v}, S_{v}$, and $G_{v}$. Note that run 12 is a continuation of run 11; the bed was not levelled between these two runs. $G_{v}$ was measured by sampling the load delivered to the head of the flume for one minute every 15 minutes. The volume was recorded, and later an empirical conversion to dry weight was determined. The average of over 200 measurements of sediment discharge for each run was taken as $G_{v}$ for that run. In the case of run 12 , no measurements were taken and the value of $G_{v}$ is interpolated from a graph of sediment load $G_{v}$ versus discharge $Q_{v}$ for five runs at the same slope.

In both well sorted and poorly sorted sediment each run lasted several days. Among the kaleidoscope of scour hole forms that occurred, a relatively simple geometry was chosen for further investigation. This geometry consisted of two mobile bed anabranches joining to form a confluence, such that neither the confluence nor the anabranch reaches immediately upstream were affected by the flume walls. Figure 4 is a vertical photograph of a confluence in well sorted sand. Only scours in which the upstream anabranches were straight and regular and the bed fairly flat for a length of at least two channel widths were measured. A single cross section of each anabranch allowed for calculation of water surface width and crosssectionally averaged depth. In Series 1 , discharge was calculated from the measurements of velocity at 0.5 of the local depth at points $0.25,0.5$, and 0.75 of the channel width from one bank using a $\frac{1}{8}$-inch (3.2-mm) Prandtl tube. In Series 2, velocity was measured by timing three surface floats (plastic beads) over $50 \mathrm{~cm}$ at each of three positions, close to either bank and in the center of the channel. Conversion to average velocity was achieved by multiplying the arithmetic mean of the nine float velocities by an empirically determined conversion factor for field anabranches of 0.72 . In Series 1 , local water surface $S_{w}$ and bed slope $S_{b}$ were also measured.

In Series 1, average particle size of the bed material in the anabranches and the scour hole was determined by scraping grains from the surface and then measuring the length of the $b$ axis of about 100 grains using a microscope with a calibrated eye piece (see Ashmore [1979] for details of the technique). In the Series 2 experiments the bed surface material was sampled using a 2-cm square of sheet metal smeared with vaseline. When applied to the bed, the vaseline picked up the surface particles. The samples were prepared for analysis by dissolving the vaseline with naptha. They were then photographed, and the $b$ axis of 100-200 grains measured from the enlarged photographs using a digitizer linked to an Apple II computer. Both techniques are assumed to give an area by number sample [Kellerhals and Bray, 1971]. Maximum scour depth (water surface to bed) could be measured accurately using a point gauge, and angle of incidence was recorded to the nearest $5^{\circ}$. Because scour hole geometry changed rapidly (usually in a few minutes), measurements had to be made quickly, and some inaccuracies, particularly in measurement of discharge, resulted. In all, 42 scour holes were measured in Series 1 and 38 in Series 2 . Bed material samples were taken for only 22 of the latter series.

\section{FigLd Procedure}

Scour data were collected from a reach of the Sunwapta River, Alberta, Canada, part of which is shr wn in Figure $5 a$. For comparison, the Series 1 and 2 model valley flats are shown in Figures $5 b$ and $5 c$. The reach of the Sunwapta River was the same as that from which Rice [1979] collected hydraulic geometry data. The annual peak flows in this part of the Sunwapta River coincide with the maximum glacial melt in midsummer. During this period, discharge fluctuates systematically in response to diurnal changes in air temperature. Measurements of scour holes were made during daily peak flows and during the discharge peaks associated with heavy rainstorms. Because parts of the river are extremely hazardous at high flows, access

TABLE 2. Summary of Parameters for Series 2

\begin{tabular}{rcccc}
\hline Run & $Q_{v}, 1 / \mathrm{s}$ & $S_{v}$ & $G_{v}, \mathrm{~g} / \mathrm{min}$ & $\begin{array}{c}\text { Number of scours } \\
\text { Measured }\end{array}$ \\
\hline 6 & 1.50 & 0.015 & 176 & 1 \\
7 & 1.50 & 0.010 & 64 & 2 \\
8 & 4.50 & 0.010 & 515 & 3 \\
10 & 2.25 & 0.015 & 320 & 5 \\
11 & 1.20 & 0.015 & 96 & 4 \\
12 & 2.50 & 0.015 & 400 & 23 \\
\hline
\end{tabular}




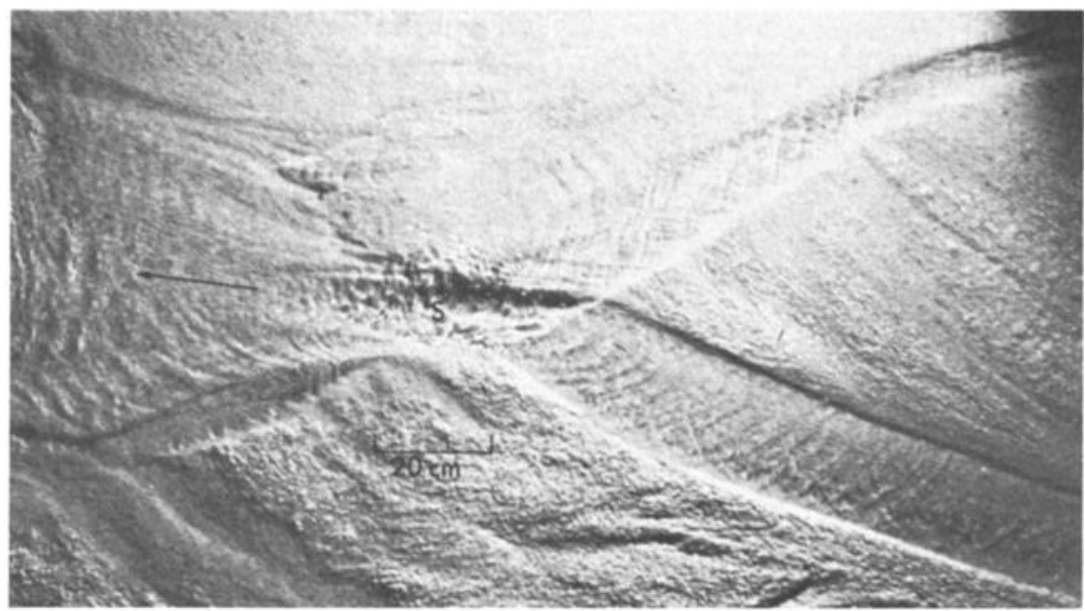

Fig. 4. Vertical photograph of scour hole at a confluence in well sorted laboratory sand. Flow right to left.

to suitable scour holes was restricted. Only channels which could be safely waded could be measured. As in the laboratory experiments, attention was focused on scour holes produced by two well defined anabranches. For each scour hole a single cross section in each anabranch and the local water surface slope was surveyed. Velocity was measured using surface floats; the velocity of three floats at each of three locations, close to either bank and at the center of the channel, was averaged to give a velocity. This method was later compared empirically with measurement using a Pygmy Price current meter at 0.6 depth from the surface at $1 \mathrm{~m}$ intervals across the channel. An average conversion from float velocity to average velocity was calculated using data from 20 channels measured by both methods. Bed material size in the anabranches was determined from $50 b$ axes of pebbles using the Wolman [1954] pacing method (equivalent to a grid by number sample). No attempt was made to sample bed material in the scour holes.

In order to make the field grid by number samples com- parable with the laboratory area by number samples, a weighted mean was calculated by multiplying each grain diameter $D_{i}$ by $1 / D_{i}{ }^{2}$ and dividing the sum by $\Sigma\left(1 / D_{i}{ }^{2}\right)$ [Leopold, 1970; Kellerhals and Bray, 1971]. Since the scraping technique used for Series 1 and the grid by number field technique tend to exclude the finest material from the sample (anything finer than $8 \mathrm{~mm}$ in the field or its equivalent on a linear scale in the lab) the fine fraction $(<0.4 \mathrm{~mm})$ from the Series 2 samples was excluded from the calculations to make the samples more comparable.

Angle of incidence was measured using a compass. Scour depth was determined by one of two methods. Whenever it was possible to wade close to the center of the scour hole, a stadia rod was used to measure maximum depth. However, where depths were over $0.7-0.8 \mathrm{~m}$ this was usually impossible, so a portable Raytheon echo sounder was used instead. The shaft of the sounder transducer was bolted vertically through a hole in a 1-m square plywood sheet mounted on two lengths of sealed

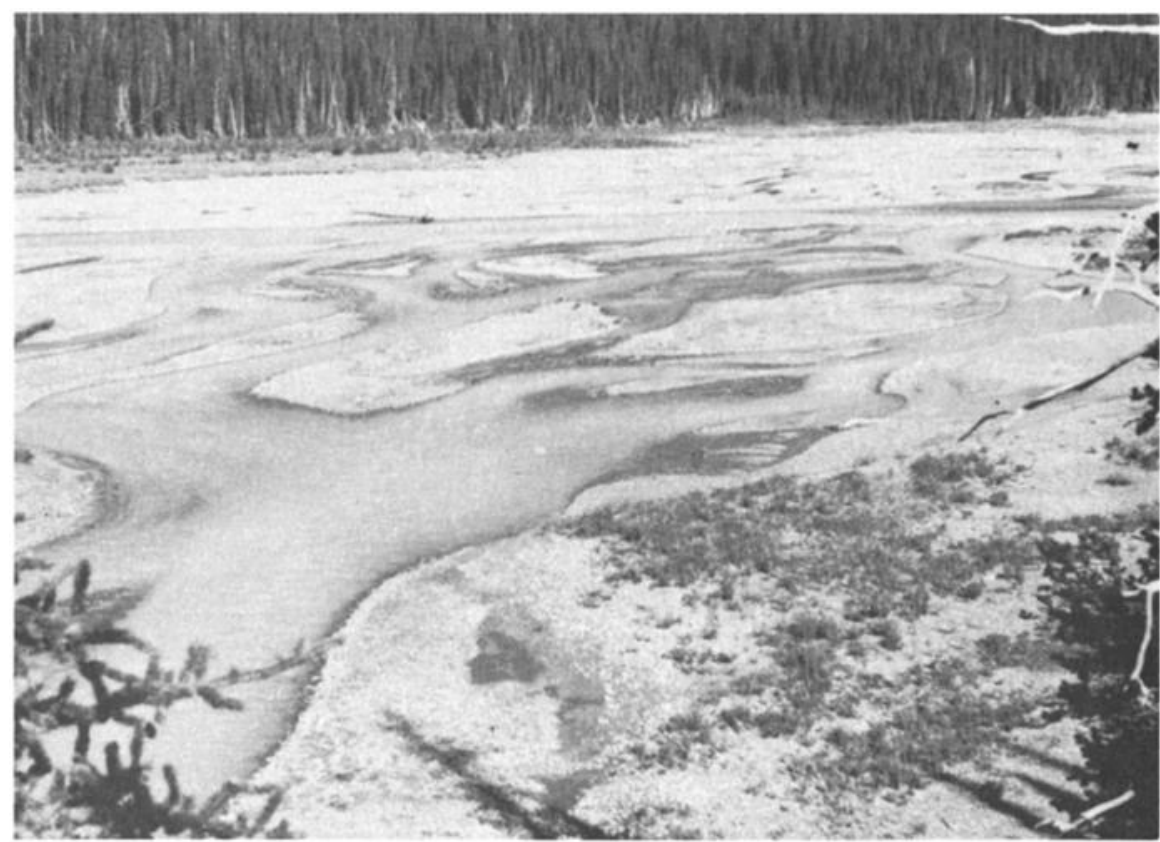

Fig. 5a. View of Sunwapta River, Alberta. 


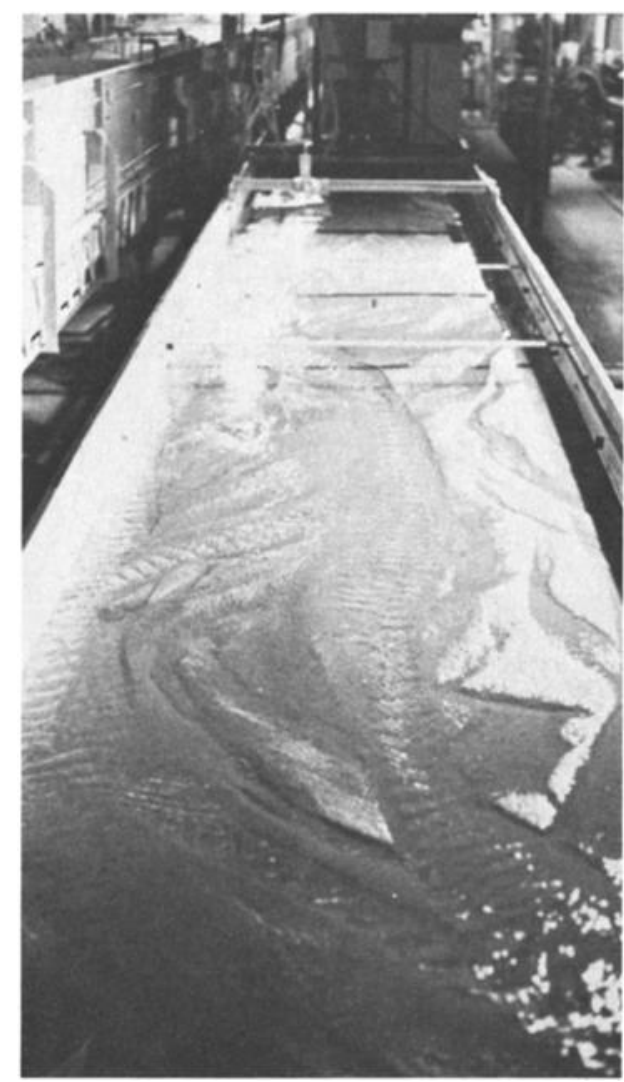

Fig. $5 b$. View of the valley flat of the Series 1 model experiments. The flow is on.

PVC pipe acting as floats. The chart recorder remained on the bank and a rope attached to the float was used to manipulate the float over the scour hole from a postion between the two anabranches. The transducer was immersed about $20 \mathrm{~cm}$ below the floats and was positioned over the longitudinal axis of the scour hole by the opposing flow of the two channels. The float could be moved along this axis by hauling in or letting out the rope. The turbulence in the scour holes resulted in considerable rolling and pitching of the float and unclear sounding races resulted. Often it was necessary to run the transducer back and forth several times over the scour hole before a consistent maximum depth was recorded. Data were collected from 23 scour holes in the Sunwapta River.

The problems of obtaining accurate data in the field are much greater than in the laboratory. This is because it is difficult to know whether the scour, at the time it is measured, is in equilibrium with the flow in the anabranches. If a scour hole remains unaltered during a fall in stage, then measurement during a relatively low stage may bear no relation to the conditions required for excavation of the scour. In the laboratory the scour hole can be observed for its whole lifetime and any changes in form are easy to see; in the field this is almost impossible.

\section{SCOUR HOLE FORM}

The simple confluence scour holes discussed here are much like Mosley's [1976]. The form of the scour hole changes with the angle of incidence. At lower angles the scour is an elongate trough, while at higher angles the scour is more basinlike (Figure 6). Superelevation of the water surface over the center of the scour is also more evident at higher angles. Figure 7 shows this superelevation and associated turbulence at a confluence scour on the Sunwapta River. In the laboratory the turbulence and superelevation are also evident. At higher angles, confluences sometimes have small submerged ridges of sediment parallel to the flow on either side of the channel at the downstream end of the scour hole. Those are formed by the movement of bed material (particularly finer particles) obliquely across the channel from the center [Ashmore, 1982]. The scour hole in Figure 4 has a pair of those ridges.

The constant migration of the braided river anabranches means that the form of a given scour hole rarely remains unchanged for more than a few minutes in the laboratory. The position of the scour hole and its orientation respond to the relative strengths (discharge or velocity) of the flow in the two anabranches. When the discharge is approximately equal in the two channels, the long axis of the scour hole bisects the angle of incidence, but if one channel is dominant, the long axis of the scour hole tends to parallel that channel. Mosley [1976] also observed this behavior in this laboratory confluence. The dominance of one channel may also result in the progressive lateral migration of the scour hole because of the growth of a sediment lobe from the larger channel, causing erosion of the bank opposite (Figure 8). Ashmore [1979] gives some examples of this process. In the field, individual scour holes rarely lasted for more than a day or two during peak flows and on occasion could be seen to change even during measurement.

The helical flow cells observed by Mosley [1976] could be traced using dye in the laboratory and were most obvious at high angles of incidence. In the field, evidence for the secondary circulation is harder to find, but ripple patterns in the sand veneer in abandoned scour holes show that such currents were present. On occasion, ripples in abandoned scour holes could be seen to have migrated obliquely and sometimes almost perpendicularly up the sides of the scour hole.

Occasionally scour holes are abandoned more or less intact following a sudden avulsion of the flow upstream. Usually, however, scour holes are filled in by the encroachment of a sediment lobe from one channel as the other gradually loses flow and the secondary circulation wanes.

\section{ANalysis AND RESUltS}

A detailed dimensional analysis would require relating maximum scour hole depth $H_{s}$ to a variety of anabranch and valley flat parameters. It was hypothesized that valley flat parameters are much less important than those of local anabranches. The work of Parker [1979] suggest that the functional relations between width, depth, discharge, grain size, and slope in selfformed coarse channels are sufficiently well defined to allow the use of only two 'independent' hydraulic parameters in describing anabranch relations. An extension to relations for confluence scour also requires a description of both the geometry of the confluence and the fact that one upstream anabranch may be stronger than the other. The two hydraulic parameters were arbitrarily chosen to be upstream densimetric Froude number $F_{0}$ and the average of the two upsteam anabranch water surface slopes, $\bar{S}_{w}$. The former is given by

$$
F_{0}=\frac{U_{0}}{\left(\operatorname{Rg} \bar{D}_{g}\right)^{1 / 2}}
$$

where

$$
U_{0}=\frac{Q_{T}}{A_{T}}
$$




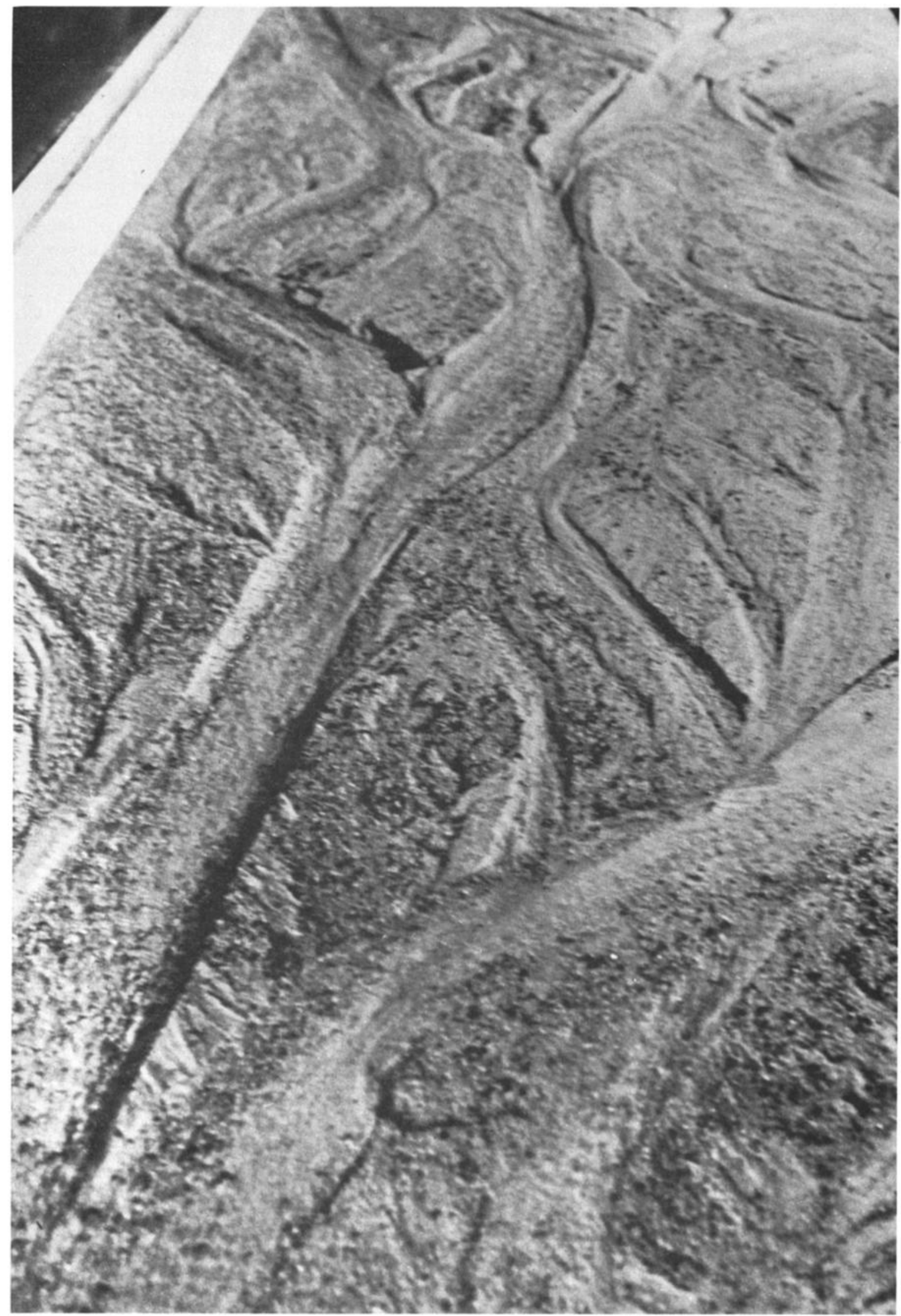

Fig. $5 c$. View of the valley flat of the Series 2 model experiments. The flow is off. The black particles are coal tracers. 
LONGITUDINAL PROFILE (a) $\theta=35^{\circ}$

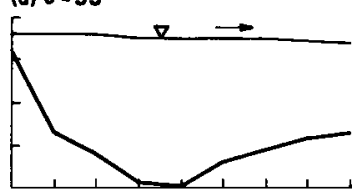

(b) $\theta=75^{\circ}$

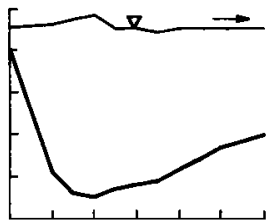

$1 \mathrm{~cm}[$
CROSS PROFILE

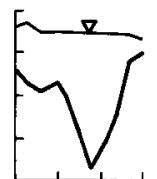

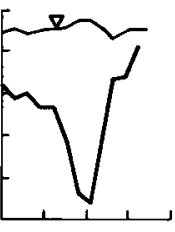

Fig. 6. Cross sections of laboratory confluence scours for confluence angles of $(a) 35^{\circ}$ and $(b) 75^{\circ}$

and

$$
\begin{gathered}
Q_{T}=Q_{R}+Q_{L} \quad A_{T}=B_{R} H_{R}+B_{L} H_{L} \\
\bar{D}_{g}=\left(D_{R g}+D_{L g}\right) / 2
\end{gathered}
$$

The subscripts $R$ and $L$ refer to the right and left anabranches. The use of $F_{0}$ was based on results obtained by Rajaratnam and Berry [1977]. Based on Mosley's [1976] work, the angle of incidence $\theta$ and the relative discharge of the upstream anabranches were chosen as descriptors of scour geometry and relative strength of the two anabranches. The relative discharge of the upstream anabranches $\varepsilon$ is given by

$$
\varepsilon=\frac{\left|Q_{L}-Q_{R}\right|}{\frac{1}{2} Q_{T}}
$$

(Note that Mosley calculated his relative discharge as simply $Q_{1} / Q_{2}$, where $\left.Q_{2}>Q_{1}\right)$.

The proposed scour relation therefore has the form

$$
r H=f\left(F_{0}, \bar{S}_{w}, \theta, \varepsilon\right)
$$

where

$$
r H=\frac{H_{s}}{\bar{H}} \quad \bar{H}=\left(H_{R}+H_{L}\right) / 2
$$

The hypothesis that valley flat parameters have no influence on scour was confirmed using the Series 1 data. When $r H$ is plotted against valley slope $S_{v}$ and dimensionless valley discharge $\tilde{Q}_{v}$, where $\tilde{Q}_{v}=Q_{v} /\left(\left(R g D_{50}\right)^{1 / 2} D_{50}{ }^{2}\right)$, no trend is evident in either plot, even though $\bar{S}_{v}$ ranges from 0.010 to 0.016 and $\tilde{Q}_{v}$ ranges from 3000 to 7000 . For the analysis of the influence of local parameters on scour depth, 15 points were added to the existing 103, eight from Mosley [1981] for field observations on the Ohau River, New Zealand $\left(S_{v}=0.0065\right)$ and 7 from $A s h$ more [1979] for scour in the well sorted laboratory sand. The dominant influence on scour depth $r H$ is the angle of incidence of the two channels, $\theta$. Figure $9 a$ shows a plot of $r H$ versus $\theta$ for all 118 points. Scatter is considerable, but the correlation coefficient between the two is significant at a level of 0.01 . The best fit least squares linear regression shown on Figure $9 a$ gives the equation

$$
r H=2.235+0.0308 \theta
$$

The residuals from this regression suggest that a linear fit overestimates scour depth at low $\left(<30^{\circ}\right)$ and high $\left(>90^{\circ}\right)$ angles. In other words, below about $35^{\circ}$ the dropoff in depth with decrease in angle is more rapid than the linear fit suggests, and above about $80^{\circ}$ the rate of increase of $r H$ with $\theta$ begins to decrease. Mosley $[1976,1977]$ observed asymptotic behavior at high angles which agrees with the observations made here. However, our data do not cover angles high enough to reproduce entirely Mosley's observations. For practical purposes the lack of naturally occurring angles greater than about $100^{\circ}$ makes it unimportant whether the relationship is asymptotic at greater angles.

Splitting the data into its component sources gives three regression lines approximately parallel to each other and the overall regression. These lines are shown in Figure $9 b$. The Series 1 and field data (both Sunwapta and Ohau) plot very close to each other and slightly above the overall line. The

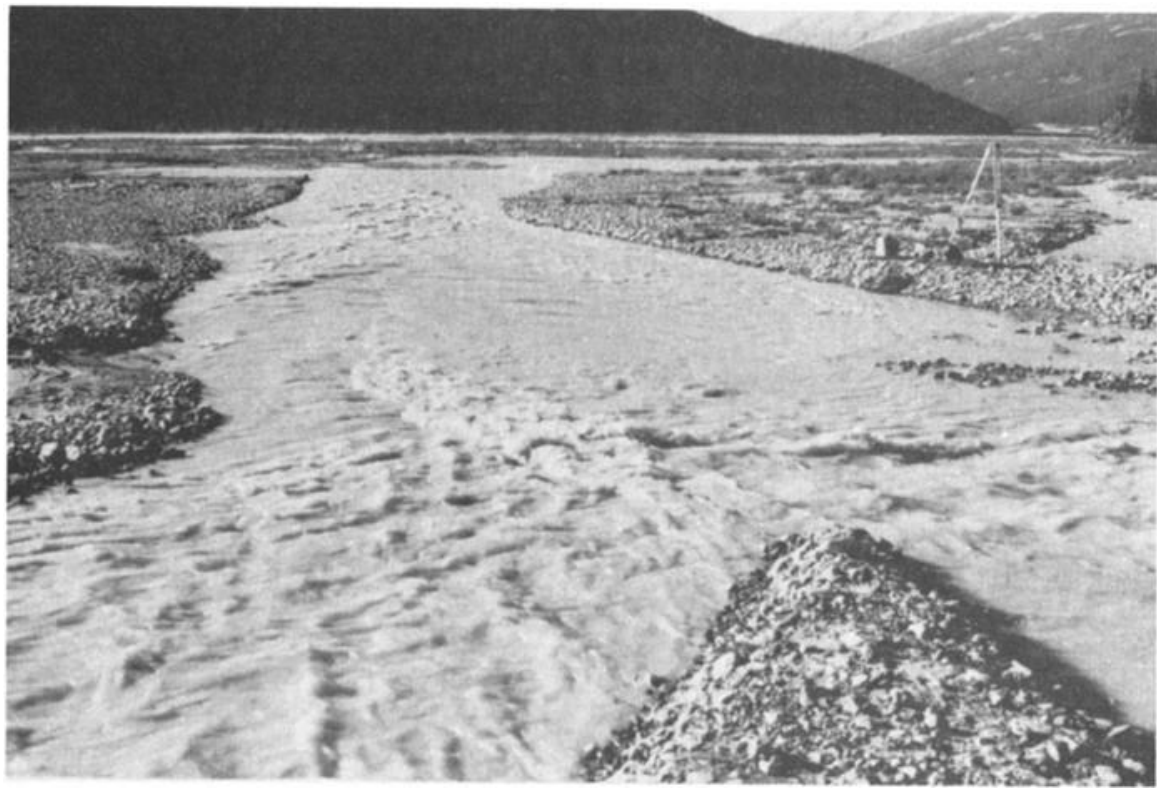

Fig. 7. View of junction on Sunwapta River, Alberta. Flow away from camera. 


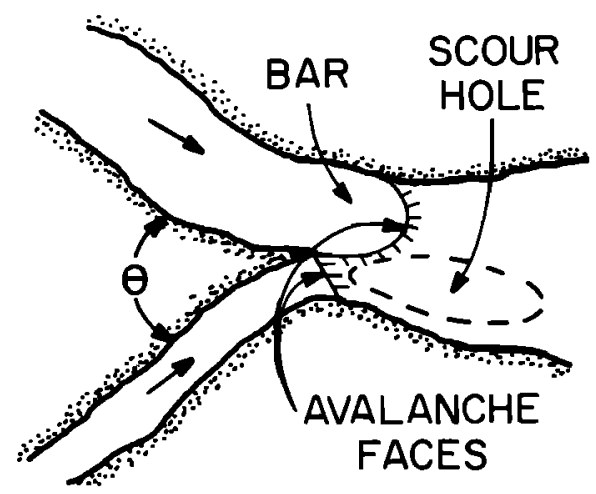

Fig. 8. When the discharges of the upstream anabranches are unequal, a bar may build out, forcing the scour hole to shift laterally.

Series 2 line plots below them. Table 3 gives the regression equations and standard error of $\bar{y}$ and $b$ for each. The $95 \%$ confidence band for $\bar{y}$ is approximately two standard errors to either side of the line, so that the prediction in the case of Series 1 is only $\pm 1 r H$ unit, and this confidence band encloses all the other regression lines (as do the confidence limits on the regression using the full data set). In other words, the lines are statistically very close to one another and any conclusions drawn from the relative position of the lines must be treated with caution. Similarly, the slopes of the regression lines (based on the standard error of $b$ given in Table 3) are indistinguishable one from another, so that, in general, the statement $r H=a+0.031 \theta$ can be applied to all data containing a range of values of $\varepsilon, F_{0}$, and $\bar{S}_{w}$. When stratified for $\varepsilon$, the relationship between $r H$ and $\theta$ is modified. Figure 10 shows the effect of this stratification. For $\varepsilon<0.75$, the relationship is steeper than the overall plot, while for $\varepsilon>0.75$, where one channel is much larger than the other, the relationship between $r H$ and $\theta$ is much weaker and the slope of the regression line is indistinguishable from zero at the $95 \%$ significance level. Again, discussion of the differences between the regression lines should be tempered with caution because statistically, there is little difference between them.

Figures $9 a$ and $9 b$ also show Mosley's [1977] data from his Figure 2 for scours in cohesive bed material with $\varepsilon=0$. The data plot well below that for noncohesive sand and gravel, but a linear regression using points with $\theta$ between $30^{\circ}$ and $90^{\circ}$ gives $r H=1.014+0.0302 \theta$. The slope of this relationship for

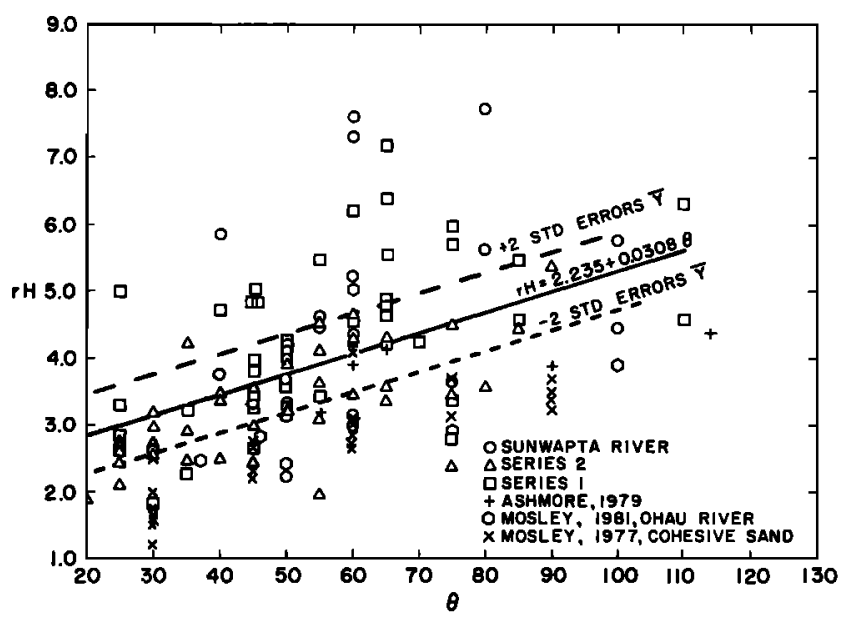

Fig. 9a. Plot of $r H$ versus $\theta$ for the complete data set.

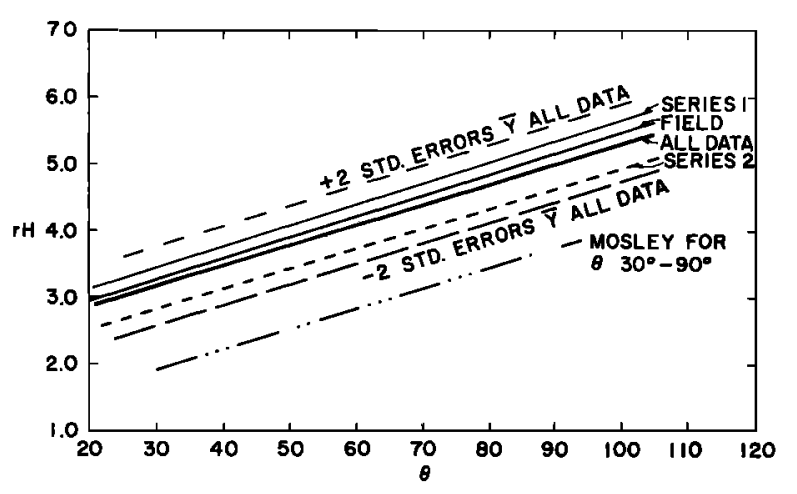

Fig. 9b. Comparison of regression lines of $r H$ Versus $\theta$ for the four separate data sets.

cohesive sediment is indistinguishable from that for noncohesive sediment, so that while the scour depth for a given angle is lower, the rate of increase in depth with $\theta$ is identical to that for noncohesive sand and gravel.

As with $\varepsilon$ the influence of densimetric Froude number $F_{0}$ (based on 86 points) and local water surface slope $\bar{S}_{w}$ (based on 65 points) on $r H$ is very weak. Plots of both these variables with $r H$ revealed no consistent trends, and attempts to discern a relationship by stratifying the samples for $\varepsilon$ and $\theta$ were also unsuccessful. Stratification of the $r H-\theta$ relationship for $F_{0}$ and $S_{w}$ also failed to reveal consistent trends.

In poorly sorted material it is possible that the scour holes may become paved with a coarse lag which might limit the scour depth. Samples of bed material from the upstream anabranches and the bed of the scour hole were taken for 42 Series 1 scours and 22 Series 2 scours. For Series 1 the average ratio of $\bar{D} g s / \bar{D} g$ (mean $b$ axis in the scourhole/mean $b$ axis of the incident anabranches) was approximately 1 with a range of 0.7 to 1.3. For the poorly sorted material in Series 2 the mean was again close to $1(0.95)$ with a range from 0.6 to 1.9 . Of the 22 scours sampled, only six showed coarser material in the scour than in the anabranches. In other words, there is no accumulation of a coarse lag in active confluence scours. This conclusion is further supported by bedload samples from the Series 2 scours in which the bedload leaving scours, on the average, was slightly coarser than that entering it. The average ratio of $\bar{D} g s / \bar{D} g$ in this case was 1.08 . These scours showed no visible accumulation of coarse material in the scours apart from occasional very large resident particles encountered during scouring. Any large particles entering the scour from upstream were moved straight through the scour.

In this context it should be pointed out that Mosley [1976, 1977] observed a reduction in depth as total sediment load

TABLE 3. Regression Summary for $r H v \theta$

\begin{tabular}{lcccc}
\hline & & & \multicolumn{2}{c}{ Standard Error } \\
\cline { 4 - 5 }$r H=a+b \theta$ & $a$ & $b$ & $\bar{y}$ & $b$ \\
\hline All data & 2.235 & 0.0308 & 0.296 & 0.0050 \\
Series 1 & 2.514 & 0.0316 & 0.517 & 0.0087 \\
Series 2 & 1.880 & 0.0307 & 0.276 & 0.0053 \\
Field & 2.354 & 0.0311 & 0.889 & 0.0144 \\
Mosley (lab data) & 1.014 & 0.0302 & 0.247 & 0.0042 \\
All data $\varepsilon<0.25$ & 2.266 & 0.0332 & 0.615 & 0.0110 \\
$\quad 0.15<\varepsilon<0.75$ & 2.036 & 0.0347 & 0.394 & 0.0064 \\
$\quad \varepsilon>0.75$ & 2.909 & 0.0120 & 0.528 & 0.0093 \\
\hline
\end{tabular}




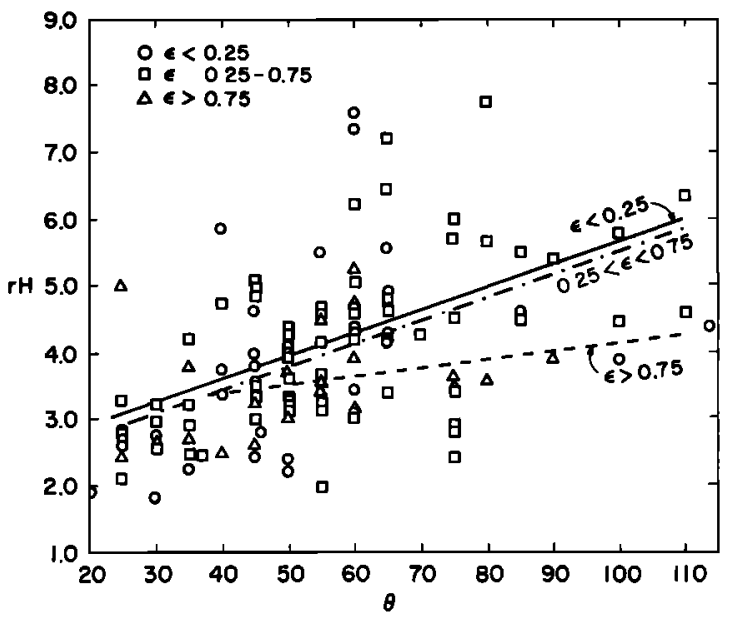

Fig. 10. Plot of $r H$ versus $\theta$ stratified for relative discharge, $\varepsilon$. (Mosley's [1977] data not included.)

increased (see earlier discussion). No attempt was made to account for this factor in this study, but observations during the Series 2 runs indicated that depths fluctuated over a range of about $3 \mathrm{~mm}$ during the measurement of some scour holes, apparently because of fluctuations in sediment load. This amounts to less than $10 \%$ of the scour depth in most cases. The size of the sediment in the scour hole could also be seen to change as a pulse of sediment moved through. This may be an important element in explaining the scatter in the relation between $r H$ and $\theta$.

\section{Discussion}

The major control of relative scour depth $r H$ has been shown to be the angle of incidence of the upstream anabranches, with only minor contributions from the relative discharge of the two channels $\varepsilon$ and the densimetric Froude number $F_{0}$. Thus the local geometry dominates over the hydraulic parameters. There is now some evidence that the bed material influences the scour depth also. This is most obvious for Mosley's data from cohesive bed material, in which scour depths are much lower than for noncohesive bed material. The differences between the well sorted and poorly sorted laboratory sand are marginal. The analysis suggests that there is a tendency for scour to be deeper in the well sorted material. The engineering literature on the effect of sediment sorting on scour is scant. The difference between the Series 1 and Series 2 data is not attributable to the development of a coarse lag, since a lag is absent from these scours. It is, however, possible to argue that a poorly sorted sediment mixture is in some bulk sense less mobile than its well sorted counterpart, both having identical mean grain sizes [Parker and Klingeman, 1982]. This lesser mobility might correspond to a relatively greater expenditure of power to move grains through the hole, with less excess power available to scour the hole deeper.

From the point of view of the applicability of the modeling of gravel bed rivers with noncohesive sand, the scour measurements support the hydraulic geometry data presented earlier, which show a good correspondence between the model and field data. Apart from the question of whether the use of well sorted instead of poorly sorted sand affects the results, which has already been discussed, the most important question is whether the models show any effects resulting from that comparatively low Reynolds numbers. Comparison of the field data and the Series 2 data, whose grain size distributions are comparable, suggest a tendency for the model to underestimate scour depth in comparison with the prototype (Figure $9 b$ ). However, the same statistical argument applies here as elsewhere, that the $95 \%$ confidence bands for the field data overlap the Series 2 regression line. This aside, the difference in depth is about one half an $r H$ unit, which for $r H=5.0$ is $10 \%$ and for $r H=3.0$ about $15 \%$. These values are tolerable for design purposes but may be of some academic concern.

The analysis suggest that a reasonable estimate of scour depth can be obtained from a knowledge of only the average depth of the channels and the angle of confluence. It should be noted that confluences are often more complex in form than those discussed here, but our laboratory observations suggest that the complex scours are not as deep as the well defined geometries discussed herein.

\section{Conclusions}

It has been shown, using field and laboratory model data, that confluence scour in gravel braided streams can be modeled reasonably well in coarse, noncohesive bed material. Scale effects, presumably resulting from low model Reynolds numbers, are not greater than about $10 \%$.

Generally speaking, $\theta$, the angle of confluence, is the major influence on scour depth $r H$, but the relationship is modified slightly by the relative discharge of the two channels when this difference becomes large. If one channel approaches twice the size of the other, the relationship with $\theta$ becomes poor. For angles between $30^{\circ}$ and $90^{\circ}$ the relationship is almost linear. Maximum relative scour depth $r H$ rarely exceeds 6.0 (only seven of 135 data points exceed $r H=6.0$ ). This relationship covers the most common naturally occurring confluence angles.

The influence of bed material sorting and cohesiveness is apparent in comparing data sets from different sources. Cohesive bed material gives markedly lower depths than noncohesive material, while poorly sorted sand may give slightly lower depths than well sorted sand of the same mean size. Coarse lag material is absent from the scour holes even in poorly sorted sand. These observations from self-formed confluence scours confirm the controls on depth first proposed by Mosley [1976] for controlled laboratory experiments.

Confluence scour depth is clearly independent of valley parameters for the range of measurements reported herein (e.g., $0.005 \leq S_{v} \leq 0.016$ ). At present, however, there is no reason to believe that the same scour relation should apply to such cases as large, low-slope sand bed braided streams.

\section{Notation}

$B$ anabranch water surface width.

$B^{*}=B / D_{g}$ or $B / D_{50}$.

$B_{R} \quad$ value of $B$ for right anabranch confluence.

$B_{L} \quad$ value of $B$ for left anabranch confluence.

$\bar{B}=\left(B_{R}+B_{L}\right) / 2$.

$B_{s}$ scour hole width.

$D_{50}$ median grain size of 'valley' sediment.

$D_{g} \quad$ anabranch mean bed surface grain size.

$\bar{D}_{g} \quad$ average of $D_{\theta}$ for left and right anabranches above confluence.

$\bar{D}_{g s} \quad$ mean grain size exposed at the bottom of scour hole.

$F_{0}$ densimetric Froude number based on average conditions upstream of confluence.

$G_{v}$ mass coarse sediment load of valley flat. 
$g$ acceleration of gravity.

$H$ cross-sectionally averaged anabranch depth.

$H_{R} \quad$ value of $H$ for right anabranch upstream of confluence.

$H_{L} \quad$ value of $H$ for left anabranch upstream of confluence.

$\bar{H}=\left(H_{R}+H_{L}\right) / 2$.

$H^{*}=H / D_{g}$ or $H / D_{50}$.

$H_{s}$ maximum depth of scour.

$Q$ anabranch discharge.

$\tilde{Q}=Q /\left(\left(R g D_{g}\right)^{1 / 2} D_{g}{ }^{2}\right)$ or $Q /\left(\left(R g D_{50}\right)^{1 / 2} D_{50}{ }^{2}\right)$.

$Q_{R} \quad$ discharge in right anabranch upstream of confluence.

$Q_{L} \quad$ discharge in left anabranch upstream of confluence.

$Q_{T}=Q_{R}+Q_{L}$.

$Q_{v} \quad$ total valley discharge.

$\widetilde{Q}_{v}=Q_{v} /\left(\left(R g D_{g}\right)^{1 / 2} D_{g}{ }^{2}\right)$.

$R \quad$ submerged specific gravity of sediment material.

$r H=H_{s} / \bar{H}$.

$S_{b}$ channel bed slope.

$S_{v} \quad$ valley slope.

$S_{w} \quad$ water surface slope.

$\bar{S}_{w} \quad$ average anabranch downstream water surface slope.

$U_{0} \quad$ average anabrancy velocity $Q_{T} / A_{T}$, where $A_{T}=B_{R} H_{R}$ $+B_{L} H_{L}$

$\varepsilon=\left|Q_{L}-Q_{R}\right| / 2 Q_{T}$.

$\theta$ angle of incidence of anabranches of confluence.

$\sigma_{g}$ geometric standard deviation of sediment $\left(D_{84} / D_{16}\right)^{1 / 2}$, where $D_{84}$ and $D_{16}$ are the size in mm such that in a sample, $84 \%$ and $16 \%$ by weight are finer, respectively.

Acknowledgments. The experimental work in Series 1 was done by A. Siu. S. Lovell provided much advice as regards technical aspects of the experiments. $\mathrm{C}$. King and $\mathbf{M}$. Dawson provided field assistance. J. Hensaker helped with programming. R. Rice made his data on the Sunwapta River available at an early date. J. Shaw provided useful ideas and discussion. M. Church, F. Blaisdell, and C. Anderson reviewed the manuscript and provided many helpful suggestions. At various stages, this research was funded or aided by the Department of the Environment of the Province of Alberta, the National Sciences and Engineering Research Council of Canada, the Killam Scholarship, St. Anthony Falls Hydraulic Laboratory, and the U. S. Geological Survey.

\section{REFERENCES}

Anderson, A. G., G. Parker, and A. Wood, The flow and stability characteristics of alluvial river channels, Project Rep. 161,116 pp., St. Anthony Falls Hydraul. Lab., Univ. of Minn., Minneapolis, 1975.

Ashmore, P., Laboratory modelling of braided streams, M. Sc. thesis, Univ. of Alberta, Edmonton, Canada, 1979.

Ashmore, P., Laboratory modelling of gravel braided stream morphology, Earth Surf. Processes, 7, 201-225, 1982.

Callander, R. A., Instability and river channels, J. Fluid Mech., 36, 465-480, 1969.

Church, M., Baffin Island sandurs: A study of arctic fluvial processes; Bull. 216, 208 pp., Geol. Surv. of Canada, Ottawa, 1972.

Doyle, P. F., and J. M. Childers, Channel erosion surveys along TAPS route, Alaska, 1975, U.S. Geol. Surv. Open File Rep., 1975.

Engelund, $F$., and $O$. Skovgaard, $O n$ the origin of meandering and braiding in alluvial streams, J. Fluid Mech., 57, 289-302, 1973.

Fahnestock, R. K., and W. C. Bradley, Knik and Matanuska Rivers, Alaska: A contrast in braiding, in Fluvial Geomorphology: Proceedings of the Fourth Annual Geomorphology Symposium, edited by M. Morisawa, pp. 221-252, State University of New York, Binghampton, New York, 1973.

Fredkin, J. F., A laboratory study of the meandering of alluvial rivers, report, 40 pp., U.S. Waterways Exp. Stn., Corps of Engineers, Vicksburg, Miss., 1945.

Galay, V. J., Some hydraulic characteristics of coarse-bed rivers, Ph.D. thesis, Univ. of Alberta, Edmonton, Canada, 1971.

Grifiths, G. A., Recent sedimentation history of the Waimakariri River, New Zealand, J. Hydrol. N. Z., 18, 6-28, 1979.

Hein, F. G., and R. G. Walker, Bar evolution and development of stratification in the gravelly, braided Kicking Horse River, British Columbia, Can. J. Earth Sci., 14, 562-570, 1977.

Henderson, F. M., Open Channel Flow, MacMillan, New York, 1966.

Hong, L. B., and T. R. H. Davies, A study of stream braiding: Summary, Bull. Geol. Soc. Am., 90, 1094-1095, 1979.

Kellerhals, R., and D. I. Bray, Sampling procedures for coarse fluvial sediments, J. Hydraul. Div. Am. Soc. Civ. Eng., 97,(HY8), 1165-1180, 1971.

Kinoshita, R., Flood flow observation by photogrammetry. Proc. Annu. Hydraul. Conf. Jpn. Soc. Civ. Eng., 23, 81-86, 1979.

Lane, E. W., A study of the shape of channels formed by natural streams in erodible materials, Sediment Ser. 9, 106 pp., U.S. Army Corps of Eng., Missouri River Div., Omaha, Neb., 1957.

Leopold, L. B., An improved method for size distribution of stream bed gravel, Water Resour. Res., 6, 1557-1566, 1970.

Leopold, L. B., and M. G. Wolman, River channel patterns: Braided, meandering, and straight, U.S. Geol. Surv. Prof. Pap. 282-B, 1957.

Mosley, M. P., An experimental study of channel confluences, J. Geol, 84, 535-562, 1976.

Mosley, M. P., Stream junctions-A probable location for bedrock placers, Econ. Geol., 72, 691-697, 1977.

Mosley, M. P., Scour depths in branch channel confluences, Ohau River, Rep. WS395, 14 pp., Water and Soil Sci. Centre, Min. of Works and Dev., Christchurch, New Zealand, 1981.

Parker, G., On the cause and characteristic scales of meandering and braiding in rivers, J. Fluid Mech., 76, 457-480, 1976.

Parker, G., Hydraulic geometry of active gravel rivers, J. Hydraul. Div. Am. Soc. Civ. Eng., 105(HY9), 1185-1201, 1979.

Parker, G., and A. G. Anderson, Modeling of meandering and braiding in rivers, paper presented at the 1975 Symposium on Modeling, Am. Soc. Civ. Eng., San Francisco, November 1975.

Parker, G., and P. C. Klingeman, On why gravel-bed streams are paved, Water Resour. Res., 18, 1409-1423, 1982.

Parker, G., S. Dhamotharan, and H. Stefan, Model experiments on mobile, paved gravel streams, Water Resour. Res., 18, 1396-1408, 1982.

Rajaratnam, N., and B. Berry, Erosion by circular turbulent wall jets, J. Hydraul. Res., 15(3), 277-290, 1977.

Rajaratnam, N., S. Pochyko, and R. K. MacDougall, Further studies on the erosion of sand beds by plane water jets, Water Resour. Eng. Rep. WRE 81, Univ. of Alberta, Edmonton, Canada, 1981.

Rice, R., Hydraulic geometry, Sunwapta River, M. S. thesis, Univ. of Alberta, Edmonton, Canada, 1979.

Schumm, S. A., and H. R. Khan, Experimental study of channel patterns, Geol. Soc. Am. Bull., 83, 1755-1770, 1972.

Smith, D. G., Aggradation of the Alexandra-North Saskatchewan River, Banff Park, Alberta, Canada, in Fluvial Geomorphology: Proceedings of the Fourth Annual Geomorphology Symposium, edited by M. Morisawa, pp. 201-219, State University of New York, Binghampton, New York, 1973.

Smith, N. D., Sedimentology and bar formation in the Upper Kicking Horse River, a braided outwash stream, J. Geol., 82, 205-223, 1974.

Southard, J. B., N. D. Smith, T. G. Drake, and R. A. Kuhnle, Field and laboratory sutidies of braiding in shallow gravel-bed streams, paper presented at the 2nd International Symposium of Fluvial Sedimentology, Keele, England, September 1981.

Wolman, M. G., A method of sampling coarse river-bed material, Eos Trans. $A G U, 35,951-956,1954$.

(Received September 14, 1981; revised October 20, 1982; accepted November 1, 1982.) 